\title{
Pulmonary Atresia with Intact Ventricular Septum: an Interprofessional Approach
}

\begin{abstract}
Keywords: Ventricular hypoplasia; Pulmonary atresia; Univentricular heart; Prostaglandins

Abstract

Introduction: Pulmonary atresia with intact ventricular septum (PAIVS) is congenital heart disease (CHD) with patent ductus arteriosus and the complete obstruction of the right ventricular outflow tract as a result of pulmonary valve atresia. It occurs in 4 to 8 per 100,000 live births, representing 1 to $3 \%$ of all heart defects in children.

Case report: A 17-year-old primigravida without previous prenata controls and her preterm newborn 30 weeks of gestation is admitted to the hospital. The infant showed signs of central cyanosis, with persistent hypoxia and metabolic acidosis; echocardiogram showed the absence of the right ventricular outflow tract (tricuspid atresia) with an intact interventricular septum, confirming the diagnosis of PA-IVS. Her evolution was slow, and she showed signs of low systemic blood flow, ultimately resulting in death.

Conclusions: PA-IVS is a rare and complex CHD with a broad spectrum of presentation. Echocardiographic imaging plays a vita role in the diagnosis of this disease. An interprofessional approach, along with clinical and imaging knowledge of this disease is essential to provide the appropriate monitoring, early guidance, and effective treatment that improves the survival rate of this anomaly.
\end{abstract}

\section{Introduction}

Heart disease is the most common congenital disorder in newborn infants, with a prevalence of 13 per 1000 live births [2]; out of this rate, $15 \%$ corresponds to cyanotic lesions, of which one third are potentially fatal [3]. Cyanosis is defined as a blue discoloration of the tissues, as a result of high concentrations of reduced hemoglobin in capillary blood, exceeding the normal $3 \mathrm{~g} / \mathrm{dL}[1]$.

The pathophysiology of cyanotic heart disease is characterized by the pass of non-oxygenated blood from the right ventricle and atrium of the heart to the left ones. They can be classified by the pulmonary blood flow rate of the patient. Pulmonary atresia with the intact ventricular septum (PA-IVS) is among the cyanotic congenital heart diseases (CHD)s with the decreased pulmonary flow [4], and is characterized by a complete obstruction of blood flow between the right ventricle and the pulmonary arteries. This causes high pressure and forces a passage of desaturated blood from the right atrium to the left, also known as an atrial septal defect (ASD), which results in cyanosis in the newborn. Due to a lack of oxygenated bloodthe body creates mechanisms to avoid hypoperfusion and death, like Patent Ductus Arteriosus (PDA). As the body creates a dependency from it, PDA is considered a surgical emergency in pediatrics $[5,6]$.

Its prevalence is 0.04 to $0.08 \%$ and represents $1 \%-3 \%$ of all heart defects in children [7]. Without interventional care, it has a $50 \%$ chance of mortality during the first 2 weeks of life and $85 \%$ in the first few months. With the advancement of new surgical techniques, longterm survival rates have improved considerably, being close to $90 \%$
Journal of

Syndromes

\author{
Serrano $\mathrm{AF}^{\text {** }}$ and Natalia $\mathrm{M}^{2}$ \\ ${ }^{1}$ Physician, Universidad de Ciencias Aplicadas y Ambientales, \\ Colombia \\ ${ }^{2}$ Department of Pediatrics, Universidad de los Andes, Colombia
}

\section{*Address for Correspondence}

Serrano AF, Universidad de Ciencias Aplicadas y Ambientales, Bogotá Colombia, Email: andreu_0609@hotmail.com

\section{Submission: July 01, 2021}

Accepted: August 03, 2021

Published: August 07, 2021

Copyright: (c) 2021 Serrano AF, et al. This is an open access article distributed under the Creative Commons Attribution License, which permits unrestricted use, distribution, and reproduction in any medium, provided the original work is properly cited.

with biventricular repair and systemic to pulmonary artery shunt, and approximately $80 \%$ with univentricular repair $[5,8]$

Its clinical spectrum is characterized by heterogeneity; It ranges from a normal right ventricle (RV) that leads to a better clinical prognosis and survival chances, to a severely hypoplastic RV that requires univentricular repair [9].

\section{Case Report}

Preterm newborn of a 17-year-old primigravida with no prenatal controls; She was admitted to the delivery room with suspected chorioamnionitis secondary to preterm premature rupture of the membranes. The admission ultrasound revealed only one ventricle heart, an indication of possible CHD. C-section was performed at 30 weeks, with a birth weight of $1,200 \mathrm{~g}-38 \mathrm{~cm}$ height, APGAR 7-7-8 at 1, 5, and 10 minutes; however, the infant showed persistent central cyanosis, nasal flaring, visible apnea, thoracoabdominal asynchrony, and audible expiratory grunt when checked with a stethoscope; With Silverman Andersen the score of 5, the airway was secured by orotracheal intubation, and the patient was transferred to the neonatal intensive care unit. Chest X-ray showed moderate cardiomegaly and sinus tachycardia was observed in the electrocardiogram (ECG). An evaluation by pediatric cardiology was performed and an echocardiogram was performed; it revealed tricuspid and pulmonary atresia, wide ASD with right-to-left shunt, hypoplastic RV, univentricular anatomy with low pulmonary flow and patency of ductus arteriosus, which confirmed the PA-IVS diagnosis. Prostaglandin E1 infusion was initiated to keep the patent ductus arteriosus open.

After stabilization and weight gain, percutaneous radiofrequency perforation of the pulmonary valve was proposed.

During her clinical stay, she deteriorated progressively, showing marked abdominal distension, leukocytosis, the elevation of acutephase reactants, and abdominal radiography displaying dilated bowel loops with asymmetric rotation and edema on the intestinal wall (Figure 1). Necrotizing enterocolitis was suspected, so the patient was placed on antibiotics. 


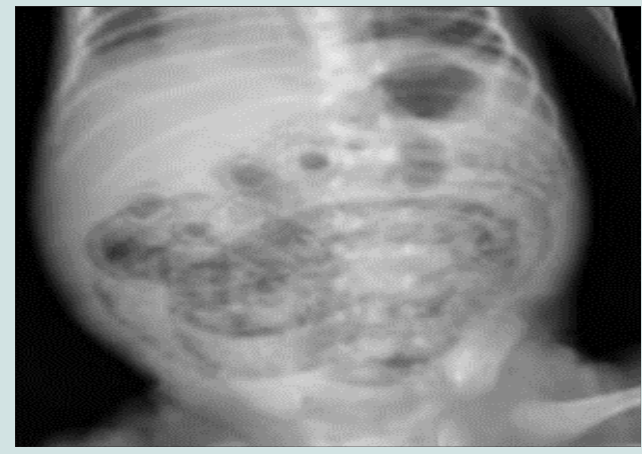

Figure 1: AP abdomen X-ray. Evidence of intestinal loop distention, and prominent intramural bowel gas. Source: Images taken from the hospital.

On the eighth day of admission her condition worsened. She showed signs of low cardiac output, persistent deep apneas with difficult recovery, altered state of consciousness, bradycardia and subsequent asystole; CPR was performed, but ultimately resulted in death.

\section{Discussion}

PA-IVS is a rare CHD characterized by the absence of blood flow from the right ventricle to the pulmonary valve due to an obstruction[10]. It is considered a critical, ductus-dependent CHD, that includes pulmonary atresia with intact ventricular septum, and variable degrees of RV hypoplasia $[9,10]$.

The first cases described were documented by Hunter, Hare and Peacock in 1783, 1853 and 1871, respectively; An intact ventricular septum was the common finding in different cases of hypoplasia of the right cavities. These case reports inspired a more thorough investigation of this anomaly, and nowadays different surgical techniques that improve the prognosis and narrow the pathophysiology of this malformation has been developed $[7,11$.

PA-IVS is a rare CHD characterized by the absence of blood flow from the right ventricle to the pulmonary valve due to an obstruction [10]. It is considered a critical, ductus-dependent CHD, that includes pulmonary atresia with an intact ventricular septum, and variable degrees of RV hypoplasia [9,10].

The first cases described were documented by Hunter, Hare, and Peacock in 1783, 1853, and 1871, respectively; An intact ventricular septum was the common finding in different cases of hypoplasia of the right cavities. These case reports inspired a more thorough investigation of this anomaly, and nowadays different surgical techniques that improve the prognosis and narrow the pathophysiology of this malformation have been developed $[7,11]$.

The pathogenesis of PA-IVS is still unclear; It has been theorized that an insult during the sensitive stages of embryological development or inflammation of the pulmonary valve that seals it after birth might be possible causes $[3,12,13]$.

Depicts the alterations that occur in the pulmonary valve, tricuspid valves, and the RV, structures that are highly compromised in PA-IVS, and were also found in the patient in the present study (Figure 2).

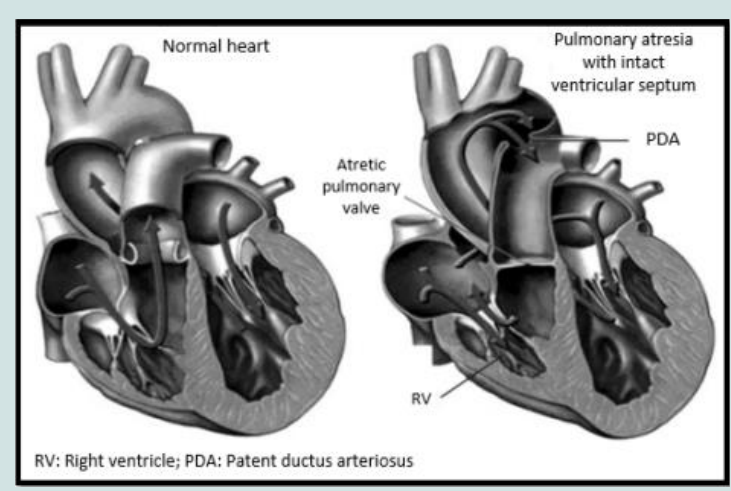

Figure 2: Pulmonary atresia with intact ventricular septum: Morphology.

\section{Retrieved from González et al. [10]}

The most common abnormality of the pulmonary valve is the fusion of its three valves, that create a thin membrane that prevents blood flow [14]; It is also possible to find an obliteration of the right ventricular infundibulum resulting in muscular infundibular atresia $[15,16]$. It is associated with a wide range of morphological and functional alterations of both the RV and the tricuspid valve, endomyocardium, and can even affect coronary circulation [15-17]. The different abnormalities associated to PA-IVS and their frequency of association can be found in Table 1 .

Retrieved from Portela et al. [9]

Pulmonary valve atresia is divided into membranous and muscular forms. It is essential to distinguish between these two types because the membranous form has a better long-term prognosis compared to its muscular version, due to the former having a higher incidence of abnormal connections between the RV and the coronary arteries $[10,18]$.

Such RV connections are known to cause (9):

Table 1: Abnormalities associated with PA-IVS.

\begin{tabular}{|c|c|}
\hline \multicolumn{2}{|c|}{ Abnormalities associated with PA-IVS } \\
\hline Ebstein'sAnomaly & $9.8 \%$ \\
\hline Pulmonaryartery hipoplasia (<3mm) & $8.7 \%$ \\
\hline RV and LV outflow tract alteration & $8,2 \%$ \\
\hline$-\quad$ Severe interventricular septal hypertrophy & $2.2 \%$ \\
\hline$-\quad$ Bicuspid aortic valve & $1.6 \%$ \\
\hline$-\quad$ Mitral valve dysplasia syndrome & $0.5 \%$ \\
\hline$-\quad$ LV hypertrophy & $0.5 \%$ \\
\hline$-\quad$ Alteration in IVS development & $0.5 \%$ \\
\hline$-\quad$ Uneurysmal tricuspid valve prolapsing over the RV outflow tract & $0.5 \%$ \\
\hline$-\quad$ Supravalvular aortic stenosis & $0.5 \%$ \\
\hline Minimum VSD & $0.5 \%$ \\
\hline Superior vena cava & $6.5 \%$ \\
\hline Aortopulmonary collateral arteries & $2.7 \%$ \\
\hline Anomalous RSA origin & $1.6 \%$ \\
\hline Anomalous RCA origin & $1.1 \%$ \\
\hline Left pulmonary vein stenosis & $1.1 \%$ \\
\hline PA-IVS: Pulmonary atresia with intact venticur septum; RCA: & $0.5 \%$ \\
\hline
\end{tabular}

PA-IVS: Pulmonary atresia with intact ventricular septum; RCA: right coronary artery; RSA: Right subclavian artery; VSD: ventricular septal defect; IVS: ventricular septum; RV: right ventricle; LV: left ventricle. 
- $\quad$ RV hypoplasia in $90 \%$ of cases.

- Right ventricular hypertension, which in turn leads to

- Sinusoids and endocardial fibroelastosis.

- Ventricular-coronary arterial connections

- Possible left ventricular obstruction.

The patient manifested cyanosis, respiratory distress, persistent hypoxemia with failed hyperoxia, and metabolic acidosis, these being the most prevalent symptoms of PA-IVS. Moderate cardiomegaly, a common finding when identifying this entity, was observed in the radiography [19]. Low cardiac output syndrome led to necrotizing enterocolitis and subsequent cardiac circulatory collapse, resulting in death.

Given the absence of prenatal check-ups, the fetal imaging guidelines were not followed in our patient. According to the American College of Obstetricians and Gynecologists, performing complete fetal echocardiography between weeks 18 and 24 on patients with suspected CHD is recommended [19-21]. The diagnosis of PA-IVS is possible with echocardiography, where the absence of the RV outflow tract and intact ventricular septum can be observed, as was the case in our patient [21]. After the PA-IVS diagnosis was completed, the patient was given prostaglandin infusion to maintain the patent ductus arteriosus open. This is vital for survival before surgery because it is one of these procedures that allow pulmonary blood flow to continue [10].

In interventional care, the degree of RV hypoplasia must be taken into account to decide upon one of these procedures; biventricular repair (separates pulmonary and systemic circulation with two functional ventricles) [5], univentricular repair (separates pulmonary and systemic circulations with only the left ventricle), and systemic to pulmonary artery shunt (separates pulmonary and systemic circulation with two ventricles, but the RV does not fully resist pulmonary circulation) [11]. A heart transplant can also be performed, especially in patients with aortocoronary atresia.

\section{Conclusions}

PA-IVS is a rare and complex CHD with wide heterogeneity. There is still unclear pathophysiology; however, it is believed that an insult during the sensitive stages of embryological development could be the reason for this.

Echocardiographic imaging plays an essential role in the diagnosis of this disease. The management of newborns with this heart defect is complex, initially seeking stabilization of the patient to continue with interventional care. It is known that an interprofessional approach, along with clinical and imaging knowledge of this disease is essential to provide appropriate monitoring, early guidance, and effective treatment to improve the survival rate of these patients.

\section{Ethical Considerations}

The present case report was carried out with the informed consent of the patient's parents, maintaining privacy and anonymity, and may serve as an alert and report to shed light on this rare disease.

\section{References}

1. Martin D, Lees H (1970) Cyanosis of the newborn infant: Recognition and clinical evaluation. J. Pediatr. 77: 484-498.

2. MD R, MJ S, Riehle-Colarusso (2008) Prevalence of congenital heart defects in metropolitan Atlanta J Pediatr 153: 807-813.

3. Reller MD, Strickland MJ, Riehle-Colarusso T, Mahle WT, Correa A (2008) Prevalence of Congenital Heart Defects in Metropolitan Atlanta, 1998-2005. J Pediatr 153: 807-813.

4. Gittenberger-De Groot AC, Eralp I, Lie-Venema H, Bartelings MM, Poelmann RE (2004) Development of the coronary vasculature and its implications for coronary abnormalities in general and specifically in pulmonary atresia without ventricular septal defect. Acta Paediatr Int J Paediatr Suppl 93: 13-19.

5. Cleuziou J, Schreiber C, Eicken A, Hörer J, Busch R, et al. (2010) Predictors for biventricular repair in pulmonary atresia with intact ventricular septum. Thorac Cardiovasc Surg 58: 339-344.

6. Gil-Jaurena JM, González-López M (2014) Atresia pulmonar con septo integro. Cir Cardiovasc 21:138-141.

7. Daubeney PEF, Delany DJ, Anderson RH, Sandor GGS, Slavik Z, et al.(2002) Pulmonary atresia with intact ventricular septum: Range of morphology in a population-based study. J Am Coll Cardiol 39: 1670-1679.

8. Kreutzer C, Mayorquim RDC, Kreutzer GOA, Conejeros W, Roman MI, et al.(1999) Experience with one and a half ventricle repair. J Thorac Cardiovasc Surg. 117: 662-668.

9. Portela F, Marcos S (2008) Atresia pulmonar con septo íntegro. Cirugía Cardiovasc 15: 337-344.

10. Morejón AEG, Ricardo GS, Ramírez FD, Sanz LM (2012) Atresia pulmonar con septum interventricular intacto. Rev Cubana Pediatr 84: 401-405.

11. Li S, Chen W, Zhang Y, Zhang H, Hua Z, et al. (2011) Hybrid therapy for pulmonary atresia with intact ventricular septum. Ann Thorac Surg 91: 14671471.

12. Maroto C, López MC, Gironaa JM, Malo P (2001) Concepción Guías de práctica clínica de la Sociedad Española de Cardiología en las cardiopatías congénitas del recién nacido. 49-66.

13. Gottschalk I, Strizek B, Menzel T, Herberg U, Breuer J, et al. (2020) Severe Pulmonary Stenosis or Atresia with Intact Ventricular Septum in the Fetus: The Natural History. Fetal Diagn Ther 47: 420-428.

14. Braunlin EA, Formanek AG, Moller JH, Edwards J (1982) Angio-pathological appearances of pulmonary valve in pulmonary atresia with intact ventricular septum. Interpretation of nature of right ventricle from pulmonary angiography. Br Heart J 47: 281-289.

15. Dyamenahalli U, McCrindle B, McDonald C, Trivedi K (2004) Pulmonary atresia with intact ventricular septum: management of, and outcomes for, a cohort of 210 consecutive patients. Cardiol Young 14: 299-308.

16. Kipps AK, Powell AJ, Levine JC (2011) Muscular infundibular atresia is associated with coronary ostial atresia in pulmonary atresia with intact ventricular septum. Congenit Heart Dis 6: 444-450.

17. Calder AL, Sage MD (1987) Coronary arterial abnormalities in pulmonary atresia with intact ventricular septum. Am J Cardiol 59: 436-442.

18. Tuo G, Volpe P, Bondanza S, Volpe N, Serafino M, et al. (2012) Impact of prenatal diagnosis on outcome of pulmonary atresia and intact ventricular septum. J Matern Neonatal Med 25: 669-674.

19. Parameters $P$ (2020) AIUM Practice Parameter for the Performance of Fetal Echocardiography. J Ultrasound Med 39: 5-16.

20. Pike JI, Krishnan A, Donofrio MT (2014) Early fetal echocardiography: Congenital heart disease detection and diagnostic accuracy in the hands of an experienced fetal cardiology program. Prenat Diagn 34: 790-796.

21. Rychik J, Ayres N, Cuneo B, Gotteiner N, Hornberger L, et al. (2004) American society of echocardiography guidelines and standards for performance of the fetal echocardiogram. J Am Soc Echocardiogr 17: 803-810. 